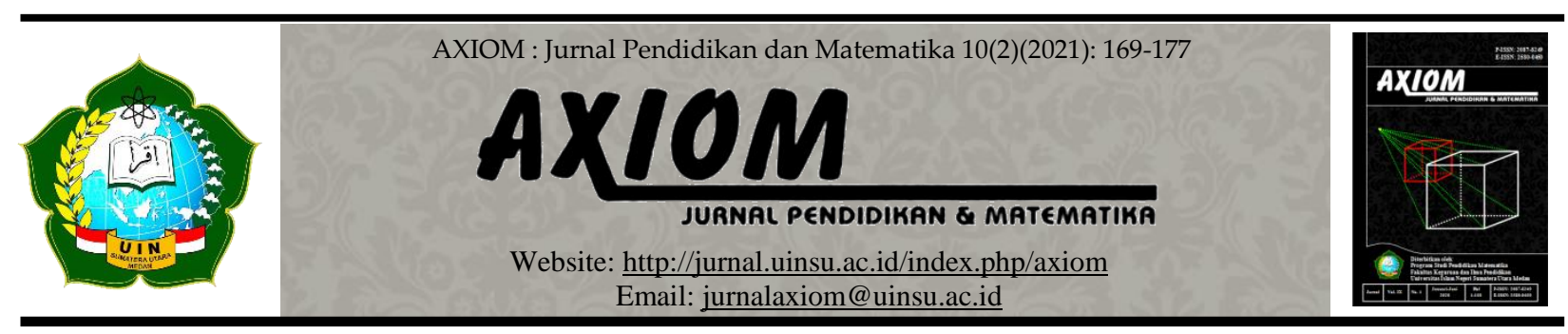

\title{
PENDUGAAN DATA HILANG PADA KASUS RANCANGAN ACAK KELOMPOK LENGKAP (RAKL) DENGAN METODE YATES
}

\section{Oleh:}

\author{
Ida Kamila ${ }^{1}$, Hendro Waryanto ${ }^{2}$, Irvana Arofah ${ }^{3}$, Besse Arnawisuda Ningsi ${ }^{4}$ \\ 1,2,3,4 Program Studi Matematika, FMIPA, Universitas Pamulang

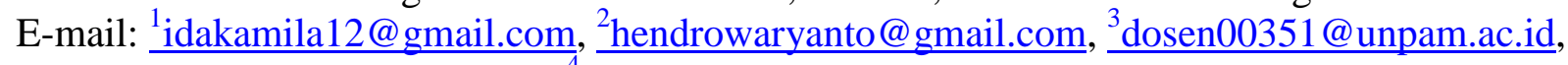 \\ dosen00205@unpam.ac.id
}

doi : 10.30821/axiom.v10i2.8734

\begin{abstract}
Abstrak:
Suhu udara sangat mempengaruhi aktivitas manusia, oleh karena itu sangat penting bagi manusia untuk mengetahui besaran suhu di daerah tertentu agar dapat mempersiapkan diri dalam beraktivitas. Untuk mengetahui besaran suhu di suatu daerah dilakukan pengukuran suhu udara. Namun dalam pengukuran suhu tidak selamanya berjalan sesuai yang direncanakan. Beberapa masalah terkadang sering terjadi seperti hasil pengukuran yang tidak teramati, fasilitas yang kurang memadai, ataupun beberapa faktor lainnya. Hal tersebut menimbulkan suatu masalah yang dikenal sebagai data hilang. Menurut data yang diperoleh dari BBMKG wilayah II terdapat dua wilayah, yaitu Stasiun Klimatologi Masgar dan Stasiun Maritim Lampung, yang masing-masing terdapat satu data hilang. Data hilang tersebut harus diduga dan diganti sebelum melakukan analisis lebih lanjut agar data yang diperoleh menjadi akurat dan valid. Metode pendugaan data hilang dalam penelitian ini menggunakan metode Yates yaitu dengan cara meminimumkan jumlah kuadrat galat. Pada Stasiun Klimatologi Masgar terdapat data hilang di bulan September 2015, sedangkan di Stasiun Maritim Lampung terdapat data hilang di bulan November 2016. Dengan metode Yates didapatkan hasil dugaan data hilang di Stasiun Klimatologi Masgar pada bulan September 2015 yaitu $27,1^{\circ} \mathrm{C}$, sedangkan di Stasiun Maritim Lampung pada bulan November 2016 yaitu $29,7^{\circ} \mathrm{C}$.
\end{abstract}

Kata Kunci:

Suhu Udara, Data Hilang, Metode Yates

\section{Abstract:}

Air temperature greatly affects human activities, so humans must know the temperature in certain areas to prepare themselves before doing activities outside. To measure the temperature of an area, air temperature measurement is carried out. However, temperature measurement does not always go as planned. Several problems sometimes occur, such as unobserved measurement results, inadequate facilities, and other factors. This creates an issue called missing data. Based on the data obtained from Meteorology, Climatology, and Geophysical Agency (Indonesian: Badan Meteorologi, Klimatologi, dan Geofisika, abbreviated as BMKG) region II, two areas have experienced a case of missing data (Masgar Climatology Station and Lampung Maritime Station). The missing data must be replaced before conducting further analysis so that the data obtained is accurate and valid. The method of estimating missing data in this study follows the Yates method that minimizes the number of squares errors. The estimation of missing data at the 
Masgar Climatology Station indicates that there was a case of missing data in September 2015. Meanwhile, there was a case of missing data in November 2016 at the Lampung Maritime Station. The findings indicate that the estimated missing data obtained at Masgar Climatology Station in September 2015 was $27,1^{\circ} \mathrm{C}$ while the estimated missing data obtained at Stasiun Maritim Lampung in November 2016 was $29,7^{\circ} \mathrm{C}$.

\section{Keywords:}

Air Temperature, Missing Data, Yates Method

\section{A. Pendahuluan}

Secara astronomis dan letak geografis, Indonesia yang diapit oleh dua samudera memberikan pengaruh angin laut yang membawa curah hujan tinggi. Hal ini meyebabkan Indonesia memiliki iklim tropis. Selain itu, letak Indonesia secara geografis juga menyebabkan Indonesia hanya memiliki dua musim, yaitu musim kemarau dan musim hujan. Hal tersebut dipengaruhi oleh angin musim yang berhembus setiap enam bulan sekali yang menyebabkan suhu di Indonesia berbeda-beda di setiap daerahnya.

Pada musim hujan, suhu udara di Indonesia akan terasa lebih dingin daripada musim kemarau. Hal tersebut menyebabkan warga negara Indonesia harus mempersiapkan diri dan meningkatkan rasa waspada bila tekanan suhu di Indonesia sedang turun menjadi dingin ataupun naik menjadi panas, agar kekebalan dan daya tahan tubuh kita selaku masyarakat Indonesia akan tetap stabil. Oleh karena itu sangat penting untuk warga negara Indonesia mengetahui suhu udara di daerahnya atau ditempatnya masing-masing agar tetap bisa menjaga aktivitas seperti biasa.

Perbedaan suhu yang dialami di Indonesia dipengaruhi oleh beberapa faktor, salah satunya adalah faktor tinggi rendahnya suatu tempat dan sudut datangnya sinar matahari. Berdasarkan data Unit Pelaksana Teknis (UPT) Balai Besar Meteorologi, Klimatologi dan Geofisika (BBMKG) Wilayah II Tangerang Selatan, Stasiun Klimatologi Masgar Lampung dan Stasiun Maritim Lampung secara geografis berada pada ketinggian 50 meter dan 1 meter di atas permukaan laut. Ditambah struktur dan orientasi kepulauan, akibatnya pola sebaran curah hujan cenderung tidak merata antara yang lain dalam ruang lingkup yang luas. Mengingat bahwa hujan di wilayah tropis banyak berpengaruh terhadap kehidupan manusia dalam segala aspeknya. Dan curah hujan ini akan berpengaruh terhadap suhu di permukaan bumi yang juga berperan penting dalam kehidupan manusia agar dapat beraktivitas. Oleh karena itu sangat penting bagi manusia mengetahui besaran suhu yang berada di daerah yang mereka tinggali.

BBMKG Wilayah II Tangerang Selatan telah mendata, mensurvei, dan mengukur ratarata suhu udara bulanan setiap bulannya namun di sini terdapat sebuah masalah yang membuat data menjadi kurang valid. Dalam suatu survei maupun penelitian seringkali terjadi suatu masalah yang tidak diinginkan, berbagai kendala dapat terjadi seperti kesalahan pada penulisan data, menginput data, cuaca yang tidak mendukung, maupun alat yang akan digunakan tidak memadai atau rusak. Kasus semacam ini sering disebut juga data hilang. Data tersebut hilang disebabkan oleh beberapa faktor yang tidak bisa di prediksi dan tidak bisa dihindari. Oleh karena itu sangat penting untuk dilakukan pendugaan data hilang. Menurut (Gomez and Gomez, 2007) hilangnya data dapat disebabkan oleh berbagai hal, misalnya perlakuan yang tidak tepat, kerusakan pada obyek percobaan, dan data yang tidak logis.

Berdasarkan data yang diperoleh dari BBMKG Wilayah II Tangerang Selatan, letak Stasiun Klimatologi Masgar Lampung berada pada ketinggian 50 meter di atas permukaan laut. Pada stasiun ini terdapat masalah data yang tidak lengkap dalam pengukuran rata-rata suhu udara bulanan. Pada tahun 2015 di bulan September terdapat satu data hilang. Stasiun Maritim Lampung berada pada ketinggian 1 meter di atas permukaan laut. Pada stasiun ini pun terjadi masalah yang sama yaitu data yang tidak lengkap atau satu data hilang pada tahun 2016 di bulan November. Oleh karena itu peneliti tertarik untuk menganalisis data yang tidak lengkap tersebut. 
Sebelum melakukan analisis, dibutuhkan rancangan percobaan dan memilih rancangan percobaan yang tepat untuk digunakan. Menurut (Hanafiah and Sukamto, 1991) apabila data percobaan dan lingkungan bersifat heterogen maka rancangan yang tepat adalah Rancangan Acak Kelompok Lengkap (RAKL). RAKL disebut rancangan acak kelompok karena pengacakan perlakuan percobaan akan dilakukan pada setiap kelompok. RAKL ini sangat baik digunakan jika keheterogenan data percobaaan yang berasal dari satu keragaman yang dapat mengatasi kesulitan pada saat mempersiapkan data percobaan yang homogen dalam jumlah yang besar. Pada RAKL, hilangnya data menyebabkan masalah yang baru dalam penelitian karena tidak memenuhi syarat keheterogenan.

Berbagai metode dapat dilakukan dalam pendugaan data hilang secara random, tetapi jika data yang tidak akurat dan hilang semakin tak terkendali atau semakin banyak maka akan sulit memprediksinya. Kondisi ini menjadikan sangat perlunya pendekatan pendugaan data hilang, agar penelitian maupun percobaan bisa berjalan lancar dan terkendali sehingga mendapatkan hasil penelitian yang valid dan ilmiah. Salah satu metode pada pendugaan data hilang yang dilihat dari kesesuaian dalam pemakaian metode yaitu jika data yang hilang satu atau dua data dapat dilakukan dengan metode Yates.

Pendugaan pada data yang hilang akan menghasilkan bias untuk jumlah kuadrat perlakuan, sehingga diperlukan bantuan penangan analisis varian sebagai alternatif untuk pengamatan yang lebih informatif untuk metode yang akan diteliti, bantuan metode ini sering disebut dengan istilah analisis varian alternatif dan setelah mendapatkan tabel analisis variannya juga untuk mengetahui adanya perbedaan pengaruh perlakuan terhadap pengamatan yang mau menguji lebih lanjut.

Suhu udara di suatu tempat berperan penting dalam aspek kehidupan manusia. Oleh karena itu jika ada suatu masalah dalam pendataan suhu udara tepatnya di Stasiun Klimatologi Masgar dan Stasiun Maritim Lampung terdapat data hilang atau tidak lengkap akan menyebabkan terganggunya aspek kehidupan manusia. Penelitian terdahulu dilakukan oleh (Sariayu, Susilawati, and Sari, 2015) yaitu menggunakan metode Yates dan Algoritma EM untuk melakukan pendugaan data hilang pada data gabah kering giling (GKG) di Kabupaten Badung tahun 2010. Dengan rancangan Lattice seimbang menghasilkan bahwa pendugaan data hilang menggunakan metode Yates cenderung lebih baik digunakan pada posisi data hilang dalam satu perlakuan, satu kolom, dan secara acak. Oleh karena itu peneliti akan menganalisis data hilang menggunakan data suhu udara pada Stasiun Klimatologi Masgar dan Stasiun Maritim Lampung dan rancangan yang digunakan adalah adalah Rancangan Acak Kelompok Lengkap (RAKL).

\section{B. Kajian Teoritis}

Suhu adalah derajat panas dari aktivitas molekul dalam atmosfer. Suhu dikatakan sebagai derajat panas atau dingin yang diukur berdasarkan skala dengan menggunakan termometer (Kartasapoetra, 1986). Pengukuran suhu atau temperatur udara dapat dinyatakan dalam skala celsius $(\mathrm{C})$, reamur $(\mathrm{R})$, dan fahrenheit $(\mathrm{F})$.

Percobaan adalah suatu tindakan atau pengamatan khusus yang dilakukan untuk memperkuat atau melemahkan/meniadakan sesuatu yang meragukan, terutama kondisi yang ditentukan oleh peneliti. Selain itu percobaan juga dapat diartikan juga sebagai suatu tindakan yang dilakukan untuk menemukan beberapa prinsip atau pengaruh yang tidak/belum diketahui serta menguji atau menjelaskan pendapat atau kebenaran yang diketahui atau diduga (Harsojuwono, Arnata, and Puspawati, 2011). Perancangan percobaan (design of experiment) adalah kajian mengenai penentuan kerangka dasar kegiatan pengumpulan informasi terhadap objek yang memiliki variasi (stokastik), berdasarkan prinsip-prinsip statistika. Bidang ini merupakan salah satu cabang penting dalam statistika inferensial dan diajarkan di banyak cabang ilmu pengetahuan di perguruan tinggi karena berkaitan erat dengan pelaksanaan percobaan (eksperimen). 
Menurut Suwanda (2011) RAKL digunakan jika unit percobaan tidak homogen sehingga perlu pengelompokkan sedemikian hingga dalam suatu kelompok relatif homogen. Tujuan pengelompokkan agar didapatkan galat yang lebih kecil. Peneliti biasanya telah melakukan percobaan dengan hati-hati, tetapi beberapa faktor di bawah kemampuan peneliti dapat menyebabkan hilangnya data. Menurut Gomez \& Gomez (2007) faktor-faktor umum penyebab hilangnya data yaitu perlakuan yang tidak tepat, kerusakan pada obyek percobaan, dan data tidak logis.

Metode Yates merupakan metode untuk analisis data hilang pada rancangan percobaan dengan cara menyisipkan nilai dugaan yang meminimumkan JKG (Jumlah Kuadarat Galat). Penanganan data hilang dengan analisis penduga data hilang pertama kali di kembangkan oleh (Yates, 1937). Prinsip dari metode Yates ini dengan meminimumkan jumlah kuadrat galat. Berbagai gambaran biofisik yang dihasilkan dari pengamatan-pengamatan terhadap petak-petak percobaan tidaklah benar-benar bersifat bebas, tetapi satu sama lain sering terlibat berhubungan secara fungsional. Pada kondisi demikian, analisis kovarian secara bersamaan dapat digunakan untuk menguji varian-varian (ragam utama) dan kovarian-kovarian (ragam pengiring) pada variabel-variabel tertentu. Pada kondisi demikian, pengujian pengaruh perlakuan akan lebih akurat apabila dianalisis menggunakan anakova dari pada menggunakan anova (Hanafiah and Sukamto, 1991).

\section{Metode Penelitian}

1. Jenis Penelitian

Jenis penelitian yang digunakan pada penelitian ini adalah penelitian kuantitatif, dimana alur penelitiannya sistematis, terencana dan terstruktur dengan jelas sejak awal hingga pembuatan rencana penelitian.

\section{Data, Intrumen, dan Teknik Pengumpulan Data}

Data yang digunakan adalah data sekunder yang bersumber dari Balai Besar Meteorologi, Klimatologi, dan Geofisika (BBMKG) Wilayah II Kota Tangerang Selatan yaitu sebanyak 118 data dari data rata-rata suhu udara bulanan 5 tahun terakhir (2014-2018). Terdapat dua kategori data yang digunakan dalam pengamatan penelitian rancangan percobaan ini yaitu: (a) Satu data hilang pada Stasiun Klimatologi Masgar. Berasal dari data rata-rata suhu udara bulanan di Stasiun Klimatologi Masgar dengan elevasi 50 meter. Data yang bersumber dari BBMKG Wilayah II Kota Tangerang Selatan diolah dari bagian managemen data. Permasalahannya adalah terdapat satu data hilang dalam data tersebut yaitu pada bulan September tahun 2015. (b) Satu data hilang pada Stasiun Maritim Lampung. Berasal dari data rata-rata suhu udara bulanan di Stasiun Maritim Lampung dengan elevasi 1 meter. Data bersumber dari BBMKG Wilayah II Kota Tangerang Selatan dan diolah dari bagian managemen data. Permasalahannya adalah terdapat satu data hilang dalam data tersebut yaitu pada bulan November tahun 2016.

\section{Teknik Analisis Data}

Dalam teknik perumusan data yang hilang, pendugaan satu atau lebih data pengamatan yang hilang dilakukan sesuai dengan rancangan apa yang digunakan (Gomez and Gomez, 2007). Menurut (Yitnosumarto, 1993) data yang hilang pada RAKL diduga dengan Rumus (1).

$$
Y_{i j}^{\prime}=\frac{r B_{j}^{\prime}+k T_{i}^{\prime}-G_{. .}^{\prime}}{(r-1)(k-1)}
$$

Keterangan:

$B_{j}^{\prime}=$ Total kelompok ke-j yang memuat data hilang

$T_{i}^{\prime}=$ Total perlakuan ke-I yang memuat dengan data hilang 
Ida Kamila, Hendro Waryanto, Irvana Arofah, Besse Arnawisuda Ningsi: Pendugaan Data Hilang Pada Kasus Rancangan Acak Kelompok Lengkap (RAKL) dengan Metode Yates

$G^{\prime} . .=$ Total pengamatan tidak termasuk data yang hilang

$k=$ Banyaknya perlakuan

$r=$ Banyaknya kelompok

Besar bias dihitung dengan Rumus (2).

$$
\text { bias }=\frac{\left\{\left(B_{j}^{\prime}-(k-1) x Y_{i j}^{\prime}\right)\right\}^{2}}{k(k-1)}
$$

Menurut (Steel, Sumantri, and Torrie, 1993) bila ada beberapa nilai yang hilang, semua nilai dilakukan dugaan awal kecuali satu. Nilai dugaan awalnya dapat diperoleh dengan Rumus (3).

$$
\frac{\left(\bar{Y}_{i .}^{\prime}+\bar{Y}_{. j}^{\prime}\right)}{2}
$$

Dengan $\bar{Y}_{i .}^{\prime}$ dan $\bar{Y}_{. j}^{\prime}$ adalah rata-rata perlakuan dan kelompok dari data yang ada, yang mengandung nilai yang hilang. Dengan menggunakan pendekatan metode Yates jika banyaknya data hilang sama dengan satu, dugaan data hilang dihitung dengan Rumus (4).

$$
\hat{Y}_{i j}=\frac{n \cdot B+t \cdot T-G}{(n-1)(t-1)}
$$

Keterangan:

$$
\begin{aligned}
& n=\sum \text { Kelompok } \\
& t=\sum \text { Perlakuan } \\
& B=\sum \text { Data Dari Kelompok Yang Mengandung Data Hilang } \\
& T=\sum \text { Data Dari Perlakuan Yang Mengandung Data Hilang } \\
& G=\text { Total Semua Pengama } \tan
\end{aligned}
$$

Nilai bias dihitung dari hasil pendugaan data hilang dengan metode Yates jika banyaknya data hilang sama dengan satu dengan Rumus (5).

$$
\text { bias }=\frac{\left\{\left(B-(t-1) \hat{Y}_{i j}\right)\right\}^{2}}{t(t-1)}
$$

\section{Hasil Penelitian dan Pembahasan}

Berdasarkan data yang diperoleh, dilakukan pengolahan data yaitu menduga data hilang pada masing-masing stasiun dengan mencari nilai jumlahan data dari kelompok yang mengandung data hilang ( $B)$, jumlahan data dari perlakuan yang mengandung data hilang $(T)$, dan mencari jumlahan total semua pengamatan $(G)$. Tabel 1 merupakan hasil pendugaan data hilang dengan menggunakan metode Yates.

Berdasarkan data pada Tabel 1, kemudian dilakukan pedugaan dengan metode Yates sebagai berikut. 


$$
\begin{aligned}
\hat{\boldsymbol{Y}}_{i j} & =\frac{n \cdot B+t \cdot T-G}{(n-1)(t-1)} \\
\hat{Y}_{29} & =\frac{12 .(107,6)+5(298,8)-1.593}{(12-1)(5-1)} \\
& =\frac{1.291,2+1.494-1.593}{(11)(4)} \\
& =\frac{2.785,2-1.593}{44} \\
& =\frac{1.192,2}{44} \\
& =27,095 \rightarrow 27,1
\end{aligned}
$$

\begin{tabular}{|c|c|c|c|c|c|c|c|c|c|c|c|c|c|}
\hline \multirow{3}{*}{ Perlakuan } & \multicolumn{12}{|c|}{ Kelompok } & \multirow{3}{*}{ Total } \\
\hline & 1 & 2 & 3 & 4 & 5 & 6 & 7 & 8 & 9 & 10 & 11 & 12 & \\
\hline & JAN & FEB & MAR & APR & MAY & JUN & JUL & AUG & SEP & OCT & NOV & DES & \\
\hline 1 & 25,7 & 26,5 & 27,1 & 27,1 & 27,3 & 26,9 & 26,8 & 26,1 & 27,1 & 27,8 & 26,9 & 26,6 & 321,9 \\
\hline 2 & 26,2 & 26,2 & 26,7 & 27,0 & 27,1 & 26,8 & 26,5 & 29,0 & - & 28,2 & 27,9 & 27,2 & 298,8 \\
\hline 3 & 27,3 & 27,1 & 27,7 & 27,5 & 27,6 & 27,0 & 26,6 & 26,8 & 27,1 & 26,9 & 27,0 & 27,0 & 325,6 \\
\hline 4 & 26,7 & 26,4 & 26,8 & 26,9 & 27,1 & 26,4 & 26,1 & 26,2 & 26,8 & 27,4 & 32,6 & 26,7 & 326,1 \\
\hline 5 & 26,6 & 26,2 & 26,3 & 27,0 & 27,0 & 26,5 & 26,2 & 26,8 & 26,6 & 27,8 & 26,4 & 27,2 & 320,6 \\
\hline Total & 132,5 & 132,4 & 134,6 & 135,5 & 136,1 & 133,6 & 132,2 & 134,9 & 107,6 & 138,1 & 140,8 & 134,7 & 1.593 \\
\hline
\end{tabular}

\begin{tabular}{|c|c|c|c|c|c|c|c|c|c|c|c|c|c|}
\hline \multirow{3}{*}{ Perlakuan } & \multicolumn{12}{|c|}{ Kelompok } & \multirow{3}{*}{ Total } \\
\hline & 1 & 2 & 3 & 4 & 5 & 6 & 7 & 8 & 9 & 10 & 11 & 12 & \\
\hline & JAN & FEB & MAR & APR & MAY & JUN & JUL & AUG & SEP & OCT & NOV & DES & \\
\hline 1 & 26,6 & 27,9 & 27,9 & 28,2 & 29,2 & 28,1 & 27,6 & 31,5 & 28,5 & 28,6 & 28,3 & 27,6 & 340 \\
\hline 2 & 27,2 & 27,6 & 27,7 & 28,2 & 26,7 & 28,1 & 27,2 & 27,9 & 28,0 & 29,9 & 28,8 & 29,1 & 336,4 \\
\hline 3 & 30,6 & 28,5 & 28,9 & 28,2 & 29,0 & 28,5 & 28,4 & 28,5 & 28,5 & 28,4 & - & 28,1 & 315,6 \\
\hline 4 & 27,8 & 27,7 & 28,1 & 28,6 & 28,7 & 27,9 & 28,7 & 28,7 & 28,8 & 29,0 & 32,1 & 28,1 & 354,2 \\
\hline 5 & 28,0 & 27,5 & 27,6 & 28,1 & 28,1 & 28,2 & 27,9 & 27,9 & 28,0 & 29,0 & 28,5 & 28,0 & 336,8 \\
\hline Total & 140,2 & 139,2 & 140,2 & 141,3 & 141,7 & 140,8 & 139,8 & 144,5 & 141,8 & 144,9 & 117,7 & 140,9 & 1.683 \\
\hline
\end{tabular}

Tabel 1. Hasil Pendugaan dengan Metode Yates Satu Data Hilang di Stasiun Masgar

$\underline{\text { Tabel 2. Hasil Pendugaan Metode Yates Satu Data Hilang Stasiun Maritim Lampung }}$

Dari data Tabel 2 kemudian dilakukan pendugaan dengan metode Yates sebagai berikut.

$$
\begin{aligned}
\hat{Y}_{i j} & =\frac{n \cdot B+t . T-G}{(n-1)(t-1)} \\
\hat{Y}_{311} & =\frac{12 \cdot(117,7)+5(315,6)-1.683}{(12-1)(5-1)} \\
& =\frac{1.412,4+1.578-1.683}{(11)(4)} \\
& =\frac{2.990,4-1.683}{44} \\
& =\frac{1.307,4}{44} \\
& =29,7
\end{aligned}
$$


Setelah mendapatkan nilai hasil dugaan dengan metode Yates, kemudian dijumlahkan dengan nilai jumlahan data dari kelompok yang mengandung data hilang $(B)$, jumlahan data dari perlakuan yang mengandung data hilang $(T)$, dan mencari jumlahan total semua pengamatan $(G)$, seperti yang terlihat pada Tabel 1 dan Tabel 2. Kemudian data tersebut dievaluasi dengan menggunakan analisis varian.

Tabel 3. Analisis Varian Satu Data Hilang Stasiun Klimatologi Masgar

\begin{tabular}{ccccc}
\hline S.K & d.b. & J.K & K.T & $\boldsymbol{F}_{\text {hitung }}$ \\
\hline Kelompok & 11 & $-42.233,392$ & $-10.558,34$ & $-7,097$ \\
Perlakuan & 4 & $-22.503,238$ & $-2.045,748$ & $-1,375$ \\
Galat & 43 & $65.458,798$ & $1.487,69$ & - \\
\hline Total & $\mathbf{5 8}$ & $\mathbf{7 2 2 , 1 6 8}$ & & - \\
\hline
\end{tabular}

Berdasarkan Tabel 3, diperoleh bahwa $F_{\text {hitung }}$ dari perlakuan $<F_{\text {tabel }}(0,01)$, maka perlakuan pendugaan data hilang pada data rata-rata suhu udara di Stasiun Klimatologi Masgar memberikan pengaruh tidak berbeda nyata.

Tabel 4. Analisis Varian Satu Data Hilang Stasiun Maritim Lampung

\begin{tabular}{ccccc}
\hline S.K & d.b. & J.K & K.T & $F_{\text {hitung }}$ \\
\hline Kelompok & 11 & $-47.078,458$ & $-11.769,614$ & $-7,101$ \\
Perlakuan & 4 & $-25.042,603$ & $-2.276,600$ & $-1,373$ \\
Galat & 43 & $72.928,451$ & $1.657,464$ & - \\
\hline Total & 58 & $-44.192,61$ & & - \\
\hline
\end{tabular}

Berdasarkan Tabel 4, diperoleh bahwa $F_{\text {hitung }}$ dari perlakuan $<F_{\text {tabel }}(0,01)$, maka perlakuan pendugaan data hilang pada data rata-rata suhu udara di Stasiun Maritim Lampung memberikan pengaruh tidak berbeda nyata. Selanjutnya menghitung nilai bias.

$$
\begin{aligned}
\text { Besar Bias } & =\frac{\left[B-(t-1) Y_{i j}\right]^{2}}{t(t-1)} \\
& =\frac{[107,6-(5-1) 29]^{2}}{5(5-1)} \\
& =\frac{[107,6-116]^{2}}{20} \\
& =\frac{70,56}{20} \\
& =3,528
\end{aligned}
$$

Karena hasil bias $F_{\text {hitung }}<F_{\text {tabel }}(0,01)$ maka hasil pendugaan data hilang pada kasus rancangan acak kelompok lengkap di Stasiun Klimatologi Masgar pada bulan September tahun 2015 tidak merubah hasil perhitungan pada metode Yates yaitu sebesar $27,1{ }^{\circ} \mathrm{C}$. 


$$
\begin{aligned}
\text { Besar Bias } & =\frac{\left[B-(t-1) Y_{i j}\right]^{2}}{t(t-1)} \\
& =\frac{[117,7-(5-1) 311]^{2}}{5(5-1)} \\
& =\frac{[117,7-1.244]^{2}}{20} \\
& =\frac{1.268,511,69}{20} \\
& =63.427,584
\end{aligned}
$$

Karena hasil bias $F_{\text {hitung }}<F_{\text {tabel }}(\mathrm{O}, \mathrm{O} 1)$ maka hasil pendugaan data hilang pada kasus rancangan acak kelompok lengkap di Stasiun Maritim Lampung pada bulan November tahun 2016 tidak merubah hasil perhitungan pada metode Yates yaitu sebesar $29,7^{\circ} \mathrm{C}$.

Hasil yang dianalisis pada analisis varian didapatkan $F_{\text {hitung }}$ dari perlakuan $<F_{\text {tabel }}(0,01)$, maka perlakuan pendugaan data hilang pada data Rata-rata Suhu Udara di Stasiun Maritim Lampung dan Stasiun Klimatologi Masgar memberikan pengaruh tidak berbeda nyata. Karena hasil bias $F_{\text {hitung }}$ dari perlakuan $<F_{\text {tabel }}(0,01)$ maka hasil pendugaan data hilang pada kasus rancangan acak kelompok lengkap di Stasiun Masgar dan Stasiun Maritim Lampung tidak merubah hasil perhitungan pada metode Yates yaitu sebesar $27,1^{\circ} \mathrm{C}$ dan $29,7^{\circ} \mathrm{C}$.

\section{E. Simpulan}

Berdasarkan analisis dan pembahasan data rata-rata suhu bulanan di Stasiun Klimatologi Masgar pada bulan September 2015 mendapatkan hasil pendugaan dengan metode Yates yaitu sebesar $27,1^{\circ} \mathrm{C}$ dan pada Stasiun Maritim Lampung didapatkan hasil dugaan dengan metode Yates pada bulan November 2016 yaitu sebesar $29,7^{\circ} \mathrm{C}$. Hasil dari penelitian ini memberikan implikasi yang positif pada pihak stasiun Masgar dan Maritim Lampung terhadap permasalahan hilangnya satu data suhu udara. Dengan hasil penelitian ini memberikan gambaran kepada Stasiun meteorologi mengenai teknis atau metode yang dapat digunakan untuk melakukan pendugaan pada kasus data hilang. Dan untuk meningkatkan kualitas penelitian maka dapat dicoba pada rancangan percobaan yang lain dengan menggunakan lebih dari satu data hilang.

\section{DAFTAR PUSTAKA}

Gomez, K., and Gomez, A. A. (2007). Prosedur Statistik untuk Penelitian Pertanian (2nd ed.). Jakarta: UI Press.

Hanafiah, K. A., and Sukamto, S. (1991). Rancangan Percobaan Teori dan Aplikasi Edisi Revisi. Jakarta: Rajagrafindo Persada.

Harsojuwono, B. A., Arnata, I. W., and Puspawati, G. A. K. D. (2011). Rancangan percobaan : Teori, aplikasi SPSS dan excel. Malang: Lintas Kata Publishing.

Kartasapoetra, A. G. (1986). Klimatologi: Pengaruh Iklim Terhadap Tanah dan Tanaman (Edisi Revisi). Jakarta: Bina Aksara.

Sariayu, N. M., Susilawati, M., and Sari, K. (2015). Pendugaan Data Hilang dengan Metode Yates dan Algoritma EM pada Rancangan Lattice Seimbang. E-Jurnal Matematika, 4(2), 74-82.

Steel, R. G. D., Sumantri, B., and Torrie, J. H. (1993). Prinsip dan prosedur statistika: Suatu pendekatan biometrik. Jakarta: PT. Gramedia Pustaka Utama.

Suwanda, S. (2011). Desain Eksperimen untuk Penelitian Ilmiah. Bandung: Alfabeta.

Yates, F. (1937). The Design and Analysis of Factorial Experiments (C. Tech, ed.). London: Imperial Bereau of Soil Science. 
Ida Kamila, Hendro Waryanto, Irvana Arofah, Besse Arnawisuda Ningsi: Pendugaan Data Hilang Pada Kasus Rancangan Acak Kelompok Lengkap (RAKL) dengan Metode Yates

Yitnosumarto. (1993). Percobaan, Analisis, dan Interpretasinya. Jakarta: PT. Gramedia Pustaka Utama. 